\title{
MOBILIDADE PENDULAR, DESCONCENTRAÇÃO ESPACIAL E AUTONOMIA MUNICIPAL NA REGIÃO METROPOLITANA DE BELO HORIZONTE *
}

\author{
Carlos Lobo** \\ Ralfo Matos *** \\ Leandro Cardoso ${ }^{* * * * *}$ \\ Eduardo Guimarães ${ }^{* * * * * *}$
}

RESUMO: As grandes cidades brasileiras, sobretudo aquelas com rápido crescimento, vêm apresentando nas últimas três décadas sinais de queda no crescimento da população. Diversos fatores têm favorecido essa tendência, tais como aqueles relacionados aos custos sociais resultantes das chamadas "deseconomias de aglomeração", além das políticas públicas destinadas a melhorar a distribuição de atividades e oportunidades. A atual organização espacial da Região Metropolitana de Belo Horizonte parece confirmar essa hipótese. Desde a década de 1970, muitos municípios da periferia, vêm apresentando incrementos populacionais mais expressivos. O propósito desse estudo é avaliar o nível de desconcentração e autonomia municipal dos municípios da Periferia Metropolitana de Belo Horizonte, tendo como base os deslocamentos pendulares da população. Utilizando os microdados amostrais dos Censos Demográficos de 1980, 2000 e 2010, foi possível identificar na maior parte dos municípios periféricos um crescimento da mobilidade, embora tenha ocorrido a redução relativa dos deslocamentos com destino ao núcleo metropolitano. Mesmo que Belo Horizonte tenha mantido sua notória centralidade regional e continue atraindo um expressivo volume dos movimentos de população, há um sensível crescimento no volume da população que trabalha no próprio município de residência, o que sugere um ganho, pelo menos relativo, de autonomia econômica da periferia metropolitana.

PALAVRAS-CHAVE: Mobilidade Pendular; Autonomia Municipal; RMBH.

\footnotetext{
* Trabalho apresentado no X Encontro Nacional sobre Migração, realizado em Natal/RN - Brasil, de 16 a 18 de outubro de 2017.

** Doutor em Geografia. Professor dos Programas de Pós-Graduação em Geografia e em Análise e Modelagem de Sistemas Ambientais, ambos do IGC/UFMG.

*** Doutor em Demografia. Professor do Programa de Pós-Graduação em Geografia do IGC/UFMG.

***** Doutor em Geografia. Professor do Programa de Pós-Graduação em Geotecnia e Transporte da Escola de Engenharia/UFMG.

****** Graduando em Geografia do IGC/UFMG. Bolsista de Iniciação Científica, CNPq.
} 


\section{INTRODUÇÃO}

Além das recorrentes controvérsias sobre a difusão de expressões como "desmetropolização", "reversão da polarização", "desconcentração e dispersão espacial”, dentre outras, há pelo menos um relativo consenso acerca das evidências empíricas de redução do ímpeto de crescimento populacional dos grandes centros metropolitanos brasileiros nas últimas décadas do século passado. Embora o processo de urbanização no Brasil seja bastante recente, intensificados a partir da segunda metade do século passado, os dados referentes aos dois últimos Censos Demográficos parecem confirmar a tendência à relativa dispersão espacial da população, mesmo que os principais centros metropolitanos tivessem mantido sua expressão demográfica regional e continuado a atrair expressivos contingentes populacionais (AZONI, 1986; DINIZ, 1993; MARTINE, 1994; MATOS, 1995; CUNHA, 2003; LOBO, 2009; LOBO e MATOS, 2011).

Nesse contexto, uma das questões que ainda tem atraído grande atenção dos estudiosos refere-se à intensificação da mobilidade espacial da população nas regiões metropolitanas. A atual distribuição espacial da população na Região Metropolitana de Belo Horizonte (RMBH) parece confirmar essa tendência. Desde a década de 1970, muitos municípios da periferia vêm apresentando incrementos populacionais mais expressivos, resultado, em boa medida, do grande volume de emigrantes procedentes do núcleo metropolitano. Essa dispersão espacial da população também teve seus reflexos na distribuição da produção de riquezas na região, o que pode ser demonstrado pela perda de participação relativa do PIB de Belo Horizonte nas últimas décadas. Cabe destacar que, afora as contribuições da Economia Regional, esse debate ainda requer aprofundamento quanto aos efeitos da distribuição espacial da população e dos movimentos espaciais da população, incluindo dados referentes aos chamados movimentos pendulares. No âmbito da Geografia, são raros os trabalhos sobre esses movimentos e mais incomuns ainda aqueles que utilizam de outras informações além das bases censitárias.

O propósito desse artigo é avaliar o nível de desconcentração e autonomia municipal dos municípios da Periferia Metropolitana de Belo Horizonte (PMBH), tendo como base nos deslocamentos pendulares da população. Para tanto, utilizou-se dos microdados da amostra dos Censos Demográficos de 1980, 2000 e 2010, tendo como unidades espaciais o recorte municipal constante do recenseamento de 2010. Essas bases permitiram identificar os movimentos específicos de residência para o local de trabalho ou estudo, o que permitiu gerar uma matriz de origem e destino entre os municípios da periferia metropolitana. A análise dos volumes permite a inclusão de dimensões pouco exploradas na abordagem tradicionais dos 
estudos sobre o processo de desconcentração e dispersão espacial da população, que comumente avalia os estoques e fluxos das atividades econômicas e da população migrante. Trazer indicadores dessa forma de mobilidade, por definição mais intensa e fluida, envolve uma reflexão mais ampla sobre a redefinição das diretrizes de ação e do público alvo das políticas de gestão e planejamento territorial metropolitano. Os diferentes níveis de desconcentração e autonomia municipal metropolitana frequentemente refletem arranjos territoriais específicos, identificados, por exemplo, pela intensidade da mobilidade no espaço, ou pela expansão do mercado de trabalho ou pelo arranjo do sistema de educacional.

\section{DESMETROPOLIZAÇÃO, DESCENTRALIZAÇÃO OU DESCONCENTRAÇÃO? EVIDENCIAS COM BASE NA MOBILIDADE ESPACIAL DA POPULAÇÃO}

A partir de meados do século passado, vários modelos buscaram avaliar o quadro de redistribuição da população e das atividades econômicas. Um dos trabalhos de referência foi proposto por Richardson (1980). Esse autor, nessa obra, estabelece como premissa central a ideia de que o crescimento continuado da concentração das atividades econômicas não leva a um perpétuo aumento da eficiência, pois os benefícios marginais derivados da escala urbana e da concentração tendem a diminuir a partir do momento em que o centro urbano atinge um determinado tamanho de população. Para Richardson, o processo de reversão da polarização caracteriza-se pela mudança de tendência na concentração econômico-espacial, a partir da qual ocorreria a dispersão espacial para fora da região central (LOBO, 2016a) ${ }^{1}$. No caso brasileiro, algumas tentativas de aplicação desse modelo foram desenvolvidas. Entretanto, as particularidades estruturais e conjunturais oferecem dificuldades adicionais para a correta inteligibilidade do fenômeno.

\footnotetext{
${ }^{1}$ Várias foram as tentativas de avaliar empiricamente evidencias sobre o processo de desconcentração/dispersão econômica e demográfica. Champion (1984) enfatiza especificamente dados demográficos, utilizando estimativas oficiais anuais da população para examinar mudanças na escala de deslocamento urbano-rural da população britânica desde os anos 1960. Os resultados apresentados revelaram que o nível de desconcentração da população no âmbito regional atingiu seu ápice no início da década de 1970. Desde então, a taxa de perda de população observada em Londres e em várias outras grandes cidades diminuiu acentuadamente. Os resultados sugerem que os diferenciais da taxa de crescimento da população entre a Grã-Bretanha metropolitana e nãometropolitanas estreitou entre os anos 1970 e 1980. Ao contrário da experiência dos EUA e de outros países europeus, a Grã-Bretanha, em meados dos anos 1980, experimentou um ressurgimento do crescimento nãometropolitanas, que teve impacto generalizado em todo o país (CHAMPION, 1994). Lipshitz (1996), ao examinar a população e a migração em Israel, no período de 1948-1992, observou que a característica mais comum foi uma desaceleração ou mesmo reversão na tendência da concentração, que vem operando amplamente na década anterior, ainda que os resultados não sejam generalizados para todas as regiões do país. Uma das conclusões do estudo foi que a maioria das pessoas que se desloca de regiões centrais escolheu como seus destinos localidades nas periferias metropolitanas.
} 
Townroe e Keen (1984), ao avaliarem o caso paulista, trazem algumas evidências concretas de reversão da polarização no Estado entre 1970 e 1980. Além da diminuição da população do núcleo, esses autores identificaram sinais claros de desconcentração espacial. Contudo, as proposições sobre o possível processo de reversão da polarização no Brasil sofreram recorrentes críticas, tanto pelas evidências empíricas observadas, como pelos indicadores e metodologias utilizadas. Azzoni (1986), por exemplo, destaca o fato de o tamanho da cidade ser considerado como indicador de economias de aglomeração, sendo crucial considerar a região central capaz de gerar um campo de atração sobre novos investimentos. A atração regional transcenderia a atração de uma cidade, a despeito de os custos locacionais serem essencialmente urbanos. No Brasil, as evidências indicavam que, longe de constituir-se um sinal de reversão da polarização, o fenômeno observado em São Paulo estaria mais próximo de um espraiamento da indústria dentro da área mais industrializada do país, em um processo do tipo "desconcentração concentrada" (AZZONI, 1986). Para Diniz (1993), todavia, após a indiscutível concentração econômica e demográfica verificada até fins dos anos de 1960, iniciou-se em um primeiro momento o processo de reversão da polarização. Ainda de acordo com esse autor, nesse mesmo trabalho, o "espraiamento" industrial brasileiro não ocorreu apenas dentro do limitado raio de $150 \mathrm{~km}$ da área metropolitana de São Paulo. Após a incontestável concentração econômica e demográfica verificada até final da década de 1960, iniciou-se, em um primeiro momento, o processo de reversão dessa polarização. Entretanto, o processo de desconcentração não teria ocorrido de modo ampliado, mas sim em espaços seletivos bem equipados e ricos em externalidades no país, refletindo, sobretudo, o espraiamento para o interior de determinados Estados. Em uma segunda fase, ocorreria a relativa reconcentração no polígono definido pela região formada por Belo Horizonte-Uberlândia-Londrina/Maringá-Porto AlegreFlorianópolis-São José dos Campos-Belo Horizonte ${ }^{2}$.

As observações feitas por Matos (1995) corroboram, em certa medida, a análise feita por Azzoni (1986) e Diniz (1993), no que tange ao controverso alcance espacial da desconcentração. Matos, no entanto, observa que esse alcance vai muito além do campo aglomerativo de Azzoni ou do polígono de desenvolvimento de Diniz. A rigor a desconcentração se dá pelos interstícios da rede urbana brasileira em expansão nos últimos 50 anos, a despeito do fato de que boa parte da expansão da urbanização nas últimas décadas

\footnotetext{
${ }^{2}$ Negri (1996) acredita ser inapropriado o polígono estabelecido por Diniz (1993), não obstante a região central ter-se beneficiado da desconcentração dos últimos 20 anos, quando ampliou sua participação na indústria nacional de $33,1 \%$ para $49,2 \%$, isto não representou incoerências frente ao crescimento fora do polígono.
} 
deriva dos efeitos multiplicadores de espraiamento da concentração urbana e industrial do Sudeste. Esse processo estimulou o adensamento da rede urbana e os vínculos de complementaridade entre as diversas centralidades. Lobo e Matos (2011), ao analisarem a dispersão espacial no Brasil nas décadas de 1980 a 2000, não confirmam a integralidade da reversão da polarização nos termos de Richardson, nem a suposta desconcentração econômico-demográfica destacada por Redwood III (1984), mas oferecem sinais de dispersão espacial da população, já proeminente em determinados casos, como na Região de Influência de São Paulo. Nessa região, o volume dos fluxos migratório direcionados para os principais polos de atração sugere tratar-se de uma forma de "dispersão polinucleada" (LOBO, 2009).

De acordo com Lobo et al. (2008), um rápido processo de crescimento urbano começou a se desenhar no Brasil a partir da década de 1940, no qual a incipiente economia industrial deu azos à emergência de uma reorganização espacial da população no território nacional. Desde então, o país presenciou um novo padrão de urbanização, essencialmente concentrador, em que a redistribuição populacional interna privilegiou os grandes centros urbanos, não obstante as tentativas governamentais de incentivar sucessivas aberturas de fronteiras agrícolas desde a década de 1930 (MARTINE, 1987; PATARRA, 1984, TASCHNER e BÓGUS, 1986). A expansão da rede urbana brasileira, apoiada em uma ampliação do mercado de trabalho urbano-industrial, refletiu-se no aumento do número de cidades $^{3}$, acompanhada de um esvaziamento do campo e incremento da população urbana. As elevadas taxas de crescimento da população urbana a partir dos anos 1950, embora num ritmo menos acelerado desde 1970, encontraram esteio no declínio da população rural. O urbano passou a representar cerca de 56\% da população total, havendo uma expressiva participação da população residente na região Sudeste. Nesse cenário, a intensificação dos fluxos migratórios campo-cidade consolidou o processo de urbanização em torno das principais capitais brasileiras. Algumas regiões urbanas passaram a se comportar como um único organismo, embora subordinado a diferentes administrações municipais. Com efeito, o governo federal determinou a criação das regiões metropolitanas, de forma que a aproximação em termos políticos e administrativos entre os municípios componentes pudesse viabilizar a resolução de problemas compartilhados. Para tanto, houve um incentivo à gestão integrada através da preferência no acesso a recursos financeiros estaduais e federais àquelas cidades que participassem da elaboração e planejamento desse novo modelo de gerenciamento. Oito, dentre as nove

\footnotetext{
${ }^{3}$ Segundo dados dos Censos Demográficos de 1950 e 1960, houve um incremento de 877 cidades no Brasil, sendo que, destas, $33 \%$ referem-se ao surgimento de cidades no Nordeste, $27 \%$ no Sudeste e $21 \%$ no Sul (BAENINGER, 1992).
} 
principais Regiões Metropolitanas (RMs) do país do país foram criadas em 1973 (São Paulo, Belo Horizonte, Porto Alegre, Recife, Salvador, Curitiba, Belém e Fortaleza), sendo, em 1974, institucionalizada a do Rio de Janeiro ${ }^{4}$.

\section{A MOBILIDADE PENDULAR METROPOLITANA: ASPECTOS TEÓRICOS, CONCEITUAIS E METODOLÓGICOS NA ANÁLISE DA RMBH}

A mobilidade pendular envolve o movimento realizado por um conjunto de indivíduos que se deslocam entre uma unidade espacial em que se localiza seu domicílio de residência e outra, onde trabalha ou estuda. Essas unidades espaciais frequentemente envolvem municípios relativamente próximos ou limítrofes, o que requer normalmente deslocamentos de curta distância. ${ }^{5}$ Ainda que seja conceitualmente distinta dos movimentos migratórios, a mobilidade pendular apresenta reflexos e efeitos similares demograficamente, uma vez que a unidade espacial de referência experimenta um acréscimo populacional temporário mais ou menos significativo ao longo do dia. De acordo com Aranha (2005),

\footnotetext{
Do ponto de vista demográfico, os deslocamentos pendulares modificam provisoriamente o volume populacional do município e aumentam ou diminuem seu tamanho dependendo das características de cada área. Assim, se o município for mais concentrador ou mais dispersor, os deslocamentos podem gerar maior ou menor demanda por serviços ou bens ou aumentar sua oferta para a população residente. (ARANHA, 2005, p. 96)
}

Se alguns municípios se "beneficiam" do aumento provisório da população, dado o incremento da demanda de vários serviços locais, outros apresentam uma condição bem diferenciada fora do turno laboral, característica das chamadas "cidades-dormitórios". De todo modo, a pendularidade caracteriza-se como um importante parâmetro e instrumento de apoio a gestão metropolitana, sendo "indicador-síntese" da interação socioeconômica entre municípios. Retratam, em grande medida, a mobilidade da força de trabalho e da população em atividade escolar, tradicionalmente consideradas variáveis definidoras do nível de

\footnotetext{
${ }^{4}$ Convém ressaltar que, ainda na década de 1960, em vários Estados o Poder Público já caminhava nessa direção, reconhecendo a questão metropolitana, colocando em prática experiências embrionárias de gestão intermunicipal, culminando com a inclusão da questão metropolitana na Constituição Federal de 1967 e na Emenda Constitucional $n^{\circ} 1$ de 1969.

${ }^{5}$ Nesses trajetos menos distantes podem-se, contudo, ser destinadas horas no deslocamento, haja vista a não existência de vias de boa qualidade e meios de transporte pouco eficientes, especialmente se existirem trechos com alto grau de densidade populacional.
} 
polarização e influência regional (CASTELLO BRANCO; FIRKOWSKI e MOURA, 2005; DURANTON, 2013; OJIMA, 2011), definidores inclusive do recorte metropolitano6.

Para Branco (2003) existe uma tendência de que nos espaços mais adensados os relacionamentos com o "core" metropolitano seriam mais intensos. Portanto, a densificação da população no território potencializa as relações socioeconômicas no âmbito metropolitano, o que pode contribuir na redução dos custos de transportes e da sua infraestrutura. Cruz (2010) considera que o espaço que define Região Metropolitana apresenta obstáculos para a execução de políticas públicas tendo em vista as grandes diferenças internas e a falta de relações relevantes entre todos os municípios metropolitanos. Para esse autor existe um impasse com relação à unidade (recorte) adequada para o planejamento no âmbito metropolitano. Ojima (2010) supõe que o padrão de cidades-dormitório, com baixo dinamismo econômico, só passa a existir quando a proporção de movimentos pendulares é mais elevada (em torno de $40 \%$ da população ocupada). ${ }^{7}$ Há também os movimentos pendulares originados do processo de "desconcentração produtiva" que, segundo Pereira e Herrero (2009), apresentam dois tipos de fluxos: de pessoas que residem em cidades do entorno e se deslocam para outras cidades do próprio entorno (entorno/entorno); e daqueles que residem no centro metropolitano e trabalham no entorno (centro/entorno). Segundo os autores, esses fluxos pendulares apontam para um possível processo de integração metropolitana multipolarizada, indicando a dinamização de subcentros econômicos da região e novos eixos de expansão urbana e demanda viária (PEREIRA e HERRERO, 2009) ${ }^{8}$.

A RMBH, criada no dia 08 junho de 1973, pela Lei Complementar $\mathrm{n}^{0} 14$, com a finalidade de realizar "serviços comuns de interesse metropolitano" (MARES GUIA, 2001, p. 409), era composta por 14 municípios, a saber: Belo Horizonte, Betim, Caeté, Contagem,

\footnotetext{
${ }^{6} \mathrm{O}$ próprio Bureau do Censo dos Estados Unidos utiliza o movimento pendular por motivo de trabalho na definição e delimitação de grandes conjuntos metropolitanos. Na França, o Institut Natitonal de la Statistique et des Etudes Economiques usa esse mesmo indicador na identificação de polarização de uma área urbana (JULIEN, 2000). Como descrevem Morrill et al. (1999, p. 730) "Over the years, the Census Bureau and OMB have tweaked and added to the standards for defining metropolitan areas, making them complex and unwieldy. Besides the obvious and logical criterion of commuting, the standards include what are behaviorally irrelevant rules - namely, that under certain circumstances the metropolitan area must have at least 100,000 people, that outlying counties must meet highly complex combinations of density and urbanization".

${ }^{7}$ Ao considerar o percentual da população economicamente ativa ocupada entre 15 a 64 anos que se desloca para o núcleo metropolitano, pode-se considerar alguns exemplos de municípios dormitórios da RMBH, Ibirité (51\%), Ribeirão das Neves (57\%), Sabará (63\%), Santa Luzia (50\%) e Vespasiano (49\%), conforme dados do Censo Demográfico de 2010 (OJIMA, 2010)

${ }^{8}$ Ao avaliar o caso francês, analisando as áreas metropolitanas de Paris, Lyon e Marseille, Aguilera (2005) observou que, ao longo da última década, as mudanças na localização dos empregos e das pessoas levaram a um crescimento do emprego nos subcentros metropolitanos, ainda que tivesse ocorrido uma queda no número de trabalhadores residentes. Os resultados obtidos por esse autor, nesse mesmo trabalho, permitiram identificar um crescimento no número de viagens de deslocamento entre os subcentros e entre alguns municípios localizados fora da área metropolitana, de modo que a elevar a distância média de deslocamento.
} 
Ibirité, Lagoa Santa, Nova Lima, Pedro Leopoldo, Raposos, Ribeirão das Neves, Rio Acima, Sabará, Santa Luzia e Vespasiano (Figura 1).

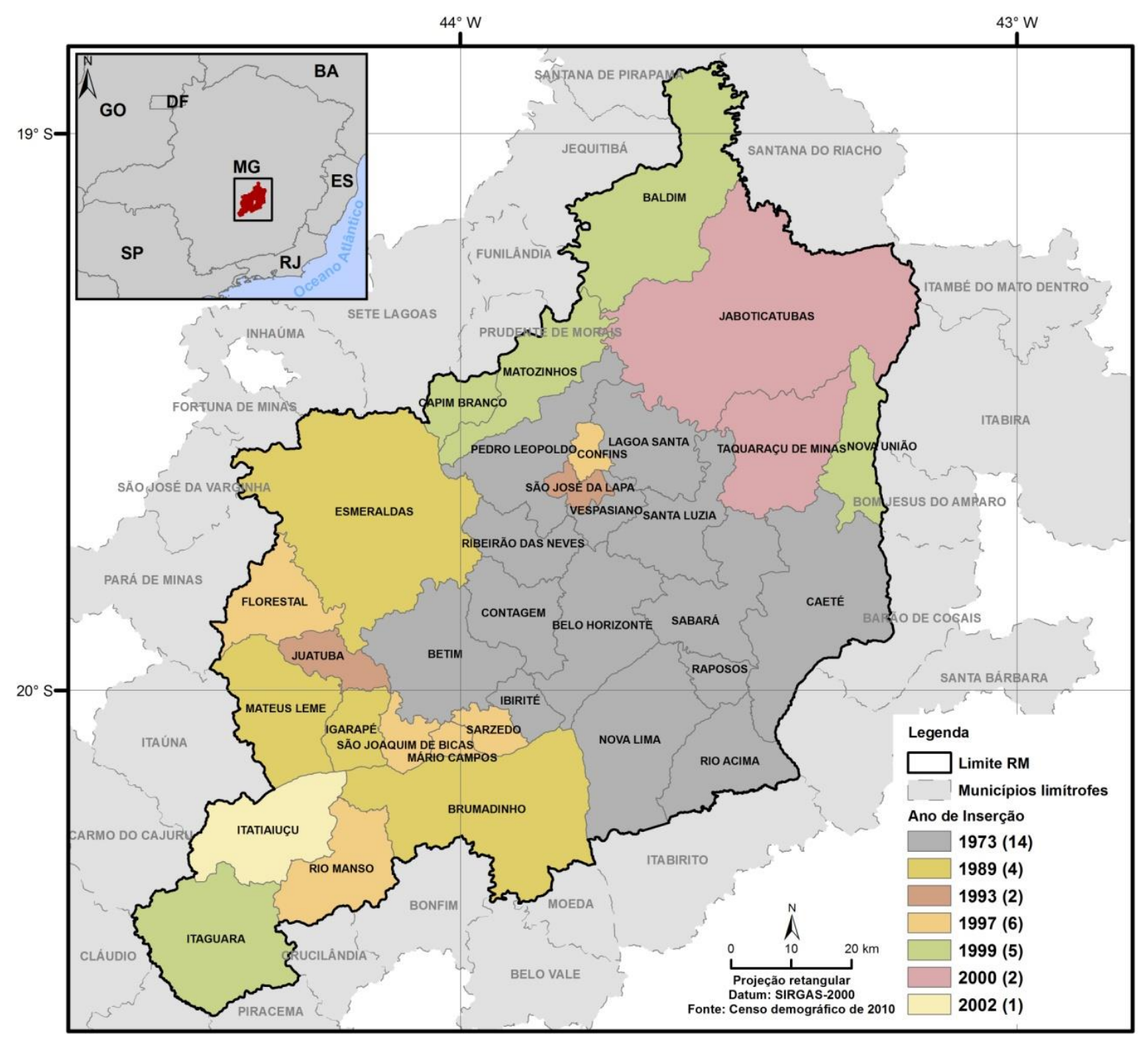

Figura 1: Formação e evolução territorial da Região Metropolitana de Belo Horizonte/MG Fonte: Elaboração própria. Base de dados Digital do IBGE - Censo Demográfico 2010.

Em 1989, com a Constituição Estadual, foram acrescentados os municípios de Brumadinho, Esmeraldas Igarapé e Mateus Leme. Em 1993, os municípios de Juatuba e São José da Lapa, antes integrantes de Mateus Leme e Vespasiano, respectivamente, foram também incorporados à região por meio da Lei Complementar $n^{\circ} 26$ (estadual). Em 1995, a Lei Estadual $\mathrm{n}^{\circ} 12.030$ determinou que municípios criados de emancipações de outras cidades pertencentes à RMBH, seriam nela, automaticamente incluídos. Com efeito, por meio da Lei Complementar (estadual) $n^{\circ} 48$, criada em novembro de 1997, foram integrados os municípios de Sarzedo e Mário Campos (pertencente a Ibirité até 1995), São Joaquim de Bicas (emancipado de Igarapé em 1995), Confins (integrante de Lagoa Santa até 1995), Florestal e Rio Manso. Em janeiro de 2000, a Lei Complementar (estadual) $\mathrm{n}^{\circ} 56$, integrou à RMBH os municípios de Baldim, Capim Branco, Itaguara, Jaboticatubas, Matozinhos, Nova União e Taquaraçu de Minas. Em 2001, o município de Itatiaiuçu também foi integrado. A RMBH é 
formada atualmente por 34 municípios e abriga cerca de 4,8 milhões de habitantes, o que a caracteriza, em termos demográficos, enquanto a terceira maior região metropolitana do país.

Lobo et al. (2014), com base na mobilidade pendular na RMBH, utilizando dados dos Censos Demográficos de 2000 e 2010, avaliaram o nível de centralidade e de dispersão espacial metropolitana. Os resultados apresentados por esses autores apontaram para uma pequena redução na proporção dos fluxos diários do tipo residência/trabalho no sentido periferia/núcleo e um crescimento mais expressivo, tanto absoluto, como relativo, dos deslocamentos na direção núcleo/periferia (denominados de pendularidade inversa). Com exemplo, verifica-se que o município de Confins teve um acréscimo superior a 300\%. Destacam-se, ainda, tanto em termos relativos como absolutos, Nova Lima e Betim, que apresentaram um incremento em torno de 50\%. As evidencias sugerem que parece ocorrer o fortalecimento de determinadas centralidades além do core metropolitano, que tem induzido uma mobilidade ampliada no espaço metropolitano (LOBO et al.,2014). Verifica-se, nesse contexto, que o core metropolitano, mesmo que mobilidade na periferia tenha experimentado um incremento considerável, mantém sua influência como fornecedora de postos de trabalho e serviços, principalmente para os ditos "municípios dormitórios"”.

\section{A PENDULARIdAdE E A DESCONCENTRAÇÃO NA RMBH: ANÁLISE E INTERPRETAÇÃO DOS RESULTADOS}

Uma primeira observação, à luz das evidências empíricas trazidas nesse exercício, diz respeito ao crescimento geral dos movimentos pendulares de população na $\mathrm{PMBH}^{10}$. Ao compararmos as três décadas analisadas ${ }^{11}$, nota-se um expressivo incremento no volume de

\footnotetext{
${ }^{9}$ A partir da década de 1970, como já demonstraram Rigotti (1994), Rigotti e Rodrigues (1994), Matos (1995), Brito (1992), dentre outros, já era perceptível uma desaceleração no ritmo de crescimento de Belo Horizonte. A partir desse momento, os municípios da periferia da RMBH vêm apresentando incrementos populacionais bem mais significativos do que a própria Capital mineira. Os diferenciais no ritmo de crescimento da periferia metropolitana tiveram reflexo na evolução da participação do núcleo metropolitano nos estoques totais de população na região. Desde 1970, a periferia metropolitana vem crescendo em volume e na proporção da população regional. Em 2000, 48,63\% da população da região metropolitana residia fora de Belo Horizonte (em 1970 essa proporção era de apenas 33,59\%). Essa queda na participação da população residente em Belo Horizonte na região metropolitana poderia suscitar pelo menos duas conclusões aparentemente antagônicas: a perda de centralidade ou a ampliação do campo de polarização do núcleo metropolitano. A primeira hipótese baseia-se em um provável deslocamento das atividades econômicas e da população do core para a periferia, diminuindo o peso econômico e demográfico da capital. Em outra perspectiva, o crescimento da periferia é visto como resultado do extravasamento do core metropolitano, o que ao contrário do que se imaginaria, representaria um crescimento da polarização e a densificação da rede urbana regional nuclear.

${ }^{10}$ Para compatibilizar o indicador de pendularidade nos três censos utilizados combinou-se os municípios de trabalho e estudo no levantamento de 2010, considerando prevalente o município de trabalho quando o de estudo for diferente.

${ }^{11}$ A década retratada pelo censo demográfico de 1991 não foi analisada pela exclusão, nesse levantamento, da variável que indicava o município de trabalho ou estudo.
} 
pessoas residentes nos municípios da Periferia Metropolitana (PM) que declararam trabalhar ou estudar em Belo Horizonte (de 82.008 em 1980 para 369.514 em 2010) ou em outro município da periferia (de 18.081 em 1980 para 134.666 em 2010), conforme dados apresentados na Tabela 1. Se considerarmos apenas os fluxos pendulares tradicionais, da periferia para o núcleo $(\mathrm{PM} \rightarrow \mathrm{NM})$, chama atenção os casos de Contagem e Ribeirão das Neves - ambos com mais de 70 mil pessoas que trabalham ou estudam no Núcleo Metropolitano (NM). Com menor volume, destacam Santa Luzia, Sabará, Ibirité, Betim, Vespasiano e Nova Lima. Esses municípios, com maior nexo com o NM, compreendem a chamada "periferia imediata" (composta pelos municípios limítrofes), especialmente aqueles da fronteira norte, oeste e leste. Se considerarmos apenas os descolamentos entre os municípios da PM, são mais relevantes os casos de Contagem e Betim, que são importantes polos industriais e comerciais da RMBH e tem atraído crescentes e expressivos contingentes de trabalhadores.

Além do crescimento total da pendularidade metropolitana, também se observa um crescimento em relação à dita população em idade ativa. Como representado na Figura 2, caiu de 26 para 19 o número de municípios que tinha menos de $10 \%$ da PIA que trabalhava/estudava em Belo Horizonte. Em contrapartida, no ano de 2010, em dois casos (Sabará e Ribeirão das Neves) essa proporção era superior a 30\%. Também é possível observar um crescimento na frequência de municípios nas classes com maior fluxo pendular no interior da própria PM. Em 1980, apenas em Capim Branco mais de 10\% da população residente trabalhava ou estudava fora do município (Figura 3). No censo de 2010 eram 10 municípios nessa condição. Em Capim Branca a proporção de trabalhadores/estudantes que se deslocava para fora do município era de $21,79 \%$. Mesmo que boa parte do aumento no número de pessoas que declaram trabalhar ou residir em Belo Horizonte ou na própria PM seja um resultado natural do crescimento populacional, especialmente a partir da década de 1970, é notório o alto grau de mobilidade populacional metropolitana. Contudo, essa maior integração via deslocamentos populacionais, especialmente dos municípios do entorno próximo da capital, (conurbação), não representa crescimento da dependência direta do mercado laboral ou educacional da capital. Como representado na Figura 4, nota-se, ao comparar as três décadas, um considerável crescimento na proporção da população que trabalha ou estuda no próprio município de residente. Em 1980 apenas em Itatiaiuçu predominava a população que não trabalhava ou estudava fora do município de residência. No entanto, em 2000 e 2010 havia 22 municípios em que mais de 50\% da PIA trabalhava ou estudava fora (em Itaguara, Taquaraçu de Minas e Rio Manso o percentual era superior a 
70\%). Mesmo aquelas localizadas na periferia do eixo norte, tradicionalmente caracterizadas como típicas “cidades dormitórios" (Santa Luzia, Vespasiano, Ribeirão das Neves e Sabará) a proporção de trabalhadores e estudantes residentes no município cresceu consideravelmente, oscilando em torno de 40\% em 2010. Destaca-se, ainda, que nas duas últimas décadas (2000 e 2010), em nenhum município essa proporção foi inferior a $30 \%$.

Os dados expostos na Tabela 2, que apresentam os valores da denominada Razão de Pendularidade (RP) ${ }^{12}$, de 1980 a 2000 e de 2000 a 2010, permitem caracterizar dois momentos distintos. Nos primeiros vinte anos, um total de doze municípios teve redução da RP (em 15 deles ocorreu um aumento). Chama atenção os casos de Sabará, Contagem e Ribeirão das Neves. Nesse último caso a RP caiu de 230,60 em 1980 para 82,54 em 2000 (o que representou a prevalência da população que trabalha ou estuda no município, nesse mesmo ano). No segundo momento, de 2000 a 2010, todos exibiram crescimento na RP. Apenas o município de Confins apresentou queda na RP (muito provavelmente em função da absorção de mão de obra decorrente da reativação/ampliação do aeroporto internacional). Contudo, ao considerar todo o período em cena, de 1980 a 2010, nota-se uma clara tendência de queda da RP. Trata-se de uma mudança decorrente não da redução dos deslocamentos pendulares (que sofreram forte incremento, como já descrito), mas do crescimento considerável da população que trabalha ou estuda na periferia metropolitana.

Esse crescimento na absorção de mão de obra nos municípios periféricos sugere um crescimento na oferta de postos de trabalho, indicando certo fortalecimento das economias locais. Mesmo que Belo Horizonte continue absorvendo parte considerável do mercado laboral metropolitano, dada a manutenção do fluxo do tipo $\mathrm{PM} \rightarrow \mathrm{NM}$, há sinais de ganho de autonomia no processo de desconcentração econômica intrametropolitano, notadamente daqueles municípios com maior peso demográfico, localizados próximos a capital. Além do fortalecimento de centros já relativamente consolidados, como Contagem e Betim, novas centralidades urbanas, ainda que em níveis inferiores de especialização e complexificação, ganham força na periferia metropolitana, especialmente no vetor norte. Alguns desses casos, não obstante suas especificidades econômicas e sociais, que receberam o rótulo de "periferia da pobreza", passaram a absorver uma maior parcela de trabalhadores e a oferecer postos de

\footnotetext{
${ }^{12}$ A RP é dada pela razão percentual entre a população que realizaram movimento pendular (seja em trabalho ou estudo em Belo Horizonte ou em outro município da PM) e aquela que trabalha e estuda no município de residência. Dessa forma, o valor 100 indica o equilíbrio numérico entre os dois grupos (pendulares e não pendulares).
} 
trabalho com maiores requisitos de qualificação e/ou especialização, sobretudo nos setores de prestação de serviços e de comércio varejista ${ }^{13}$.

Tabela 1: População da RMBH que trabalhava/estudava no município de residência (não pendulares), ou que trabalhava/estudava em Belo Horizonte ou em outro município na Periferia Metropolitana (PM) em 1980, 2000 e 2010

\begin{tabular}{|c|c|c|c|c|c|c|c|c|c|}
\hline \multirow{4}{*}{ Município } & \multicolumn{9}{|c|}{ Local de Trabalho/Estudo } \\
\hline & \multirow{2}{*}{\multicolumn{3}{|c|}{ No município de residência }} & \multicolumn{6}{|c|}{ Fora do município de residência } \\
\hline & & & & \multicolumn{3}{|c|}{ Em Belo Horizonte } & \multicolumn{3}{|c|}{$\mathrm{Na} \mathrm{PM}$} \\
\hline & 1980 & 2000 & 2010 & 1980 & 2000 & 2010 & 1980 & 2000 & 2010 \\
\hline Baldim & 2.236 & 3.882 & 3.891 & 37 & 104 & 124 & 26 & 199 & 222 \\
\hline Betim & 22.065 & 127.623 & 181.844 & 2.398 & 19.097 & 27.794 & 1.733 & 15.473 & 24.276 \\
\hline Brumadinho & 4.864 & 12.262 & 17.834 & 524 & 1.303 & 1.958 & 196 & 592 & 995 \\
\hline Caeté & 8.469 & 15.504 & 17.911 & 348 & 2.132 & 2.816 & 185 & 1.184 & 2.232 \\
\hline Capim Branco & 973 & 2.881 & 3.399 & 30 & 208 & 229 & 507 & 1.066 & 1.512 \\
\hline Confins & $\mathrm{xxx}$ & 1.898 & 2.984 & $\mathrm{xxx}$ & 113 & 228 & $\mathrm{xxx}$ & 557 & 619 \\
\hline Contagem & 61.286 & 217.364 & 270.981 & 33.440 & 66.988 & 85.552 & 6.367 & 16.203 & 25.271 \\
\hline Esmeraldas & 5.217 & 17.090 & 22.662 & 207 & 2.993 & 5.968 & 121 & 3.612 & 6.443 \\
\hline Florestal & 1.446 & 2.671 & 3.580 & 83 & 40 & 178 & 161 & 148 & 477 \\
\hline Ibirité & 5.680 & 35.442 & 46.730 & 4.376 & 22.045 & 33.567 & 2.136 & 9.393 & 15.210 \\
\hline Igarapé & 4.491 & 11.205 & 16.221 & 215 & 388 & 710 & 353 & 1.549 & 2.909 \\
\hline Itaguara & 3.358 & 5.652 & 7.114 & 7 & 146 & 193 & 32 & 205 & 270 \\
\hline Itatiaiuçu & 1.878 & 4.196 & 5.302 & 12 & 74 & 54 & 51 & 221 & 348 \\
\hline Jaboticatubas & 3.496 & 6.872 & 8.829 & 14 & 265 & 630 & 3 & 194 & 379 \\
\hline Juatuba & $\mathrm{xxx}$ & 7.037 & 10.258 & $\mathrm{xxx}$ & 389 & 644 & $\mathrm{xxx}$ & 1.038 & 1.873 \\
\hline Lagoa Santa & 5.387 & 17.694 & 26.492 & 487 & 1.947 & 4.377 & 361 & 1.302 & 2.359 \\
\hline Mário Campos & $\mathrm{xxx}$ & 3.823 & 4.893 & $\mathrm{xxx}$ & 823 & 1.228 & $\mathrm{xxx}$ & 732 & 1.677 \\
\hline Mateus Leme & 5.833 & 11.218 & 13.681 & 287 & 566 & 679 & 325 & 1.010 & 1.702 \\
\hline Matozinhos & 4.489 & 14.311 & 17.123 & 261 & 832 & 1.049 & 852 & 1.507 & 2.373 \\
\hline Nova Lima & 9.750 & 28.009 & 37.335 & 3.105 & 7.155 & 12.758 & 866 & 1.398 & 2.535 \\
\hline Nova União & 981 & 2.482 & 2.723 & 93 & 240 & 205 & 36 & 96 & 206 \\
\hline Pedro Leopoldo & 10.102 & 25.216 & 28.253 & 637 & 1.764 & 3.113 & 570 & 1.862 & 3.781 \\
\hline Raposos & 1.814 & 4.489 & 4.168 & 998 & 1.754 & 2.514 & 660 & 1.077 & 1.946 \\
\hline Ribeirão das Neves & 6.246 & 72.117 & 93.287 & 13.614 & 51.135 & 73.907 & 789 & 8.392 & 13.994 \\
\hline Rio Acima & 999 & 3.174 & 4.118 & 189 & 444 & 819 & 158 & 343 & 536 \\
\hline Rio Manso & 1.460 & 2.347 & 2.970 & 0 & 45 & 95 & 6 & 92 & 243 \\
\hline Sabará & 8.450 & 36.010 & 39.223 & 13.102 & 24.065 & 34.318 & 792 & 2.396 & 3.438 \\
\hline Santa Luzia & 12.387 & 59.301 & 72.591 & 6.650 & 35.185 & 44.429 & 516 & 4.394 & 5.648 \\
\hline São Joaquim de Bicas & $\mathrm{xxx}$ & 7.428 & 10.536 & $\mathrm{xxx}$ & 414 & 580 & $\mathrm{xxx}$ & 1.109 & 2.410 \\
\hline São José da Lapa & $\mathrm{xxx}$ & 5.547 & 7.765 & $\mathrm{xxx}$ & 1.517 & 2.804 & $\mathrm{xxx}$ & 1.000 & 1.550 \\
\hline Sarzedo & $\mathrm{xxx}$ & 6.240 & 9.537 & $\mathrm{xxx}$ & 1.655 & 2.905 & $\mathrm{xxx}$ & 1.108 & 3.121 \\
\hline Taquaraçu de Minas & 901 & 1.781 & 2.094 & 31 & 39 & 121 & 31 & 43 & 107 \\
\hline Vespasiano & 6.359 & 25.182 & 36.420 & 863 & 12.619 & 22.967 & 248 & 2.297 & 4.006 \\
\hline Total & 200.617 & 797.947 & 1.032 .747 & 82.008 & 258.483 & 369.514 & 18.081 & 81.790 & 134.666 \\
\hline
\end{tabular}

Fonte: Censos Demográficos de 1980, 2000 e 2010 (dados da amostra)

\footnotetext{
${ }^{13}$ Os municípios mais distantes já apresentavam menor nível de integração, tendo em vista as dificuldades naturais do deslocamento em longa distância.
} 


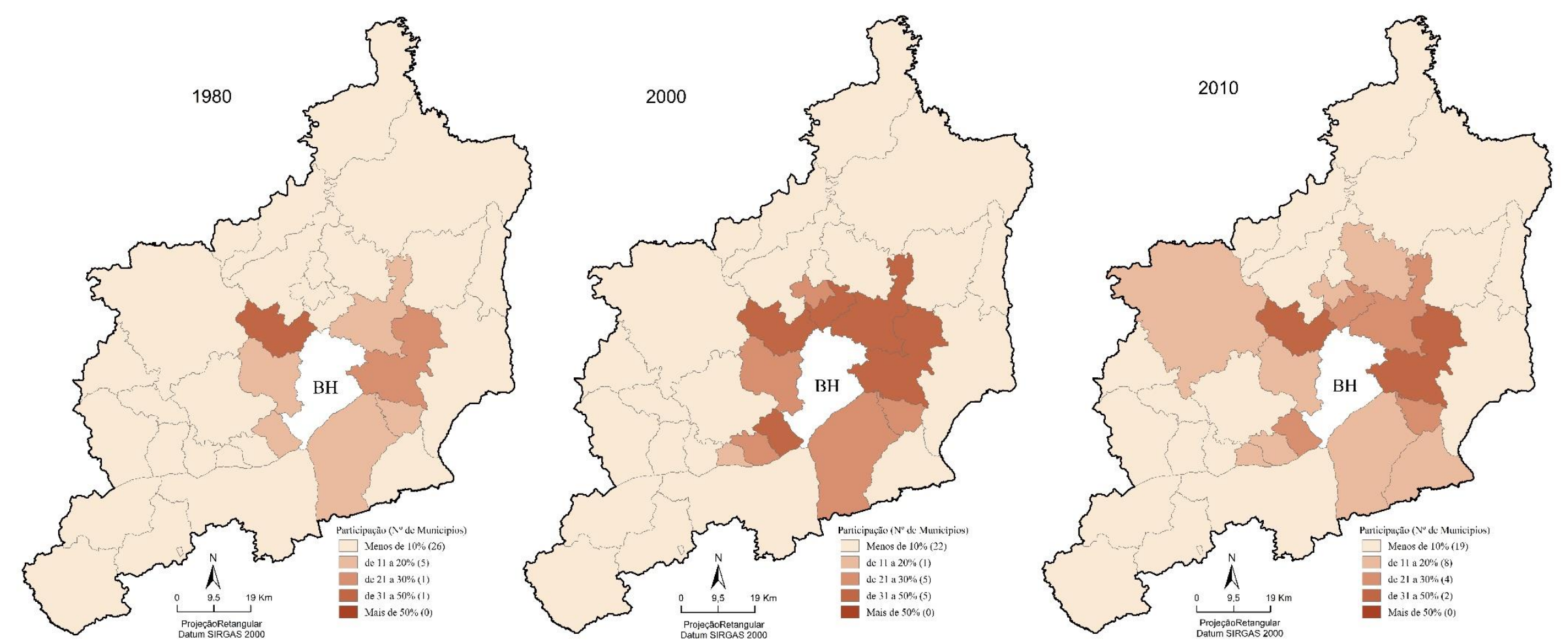

Figura 2: Participação relativa da população que trabalha e estuda em Belo Horizonte na PIA dos municípios da PMBH - 1980, 2000 e 2010

Fonte: Censos Demográficos de 1980, 2000 e 2010 (dados da amostra) 


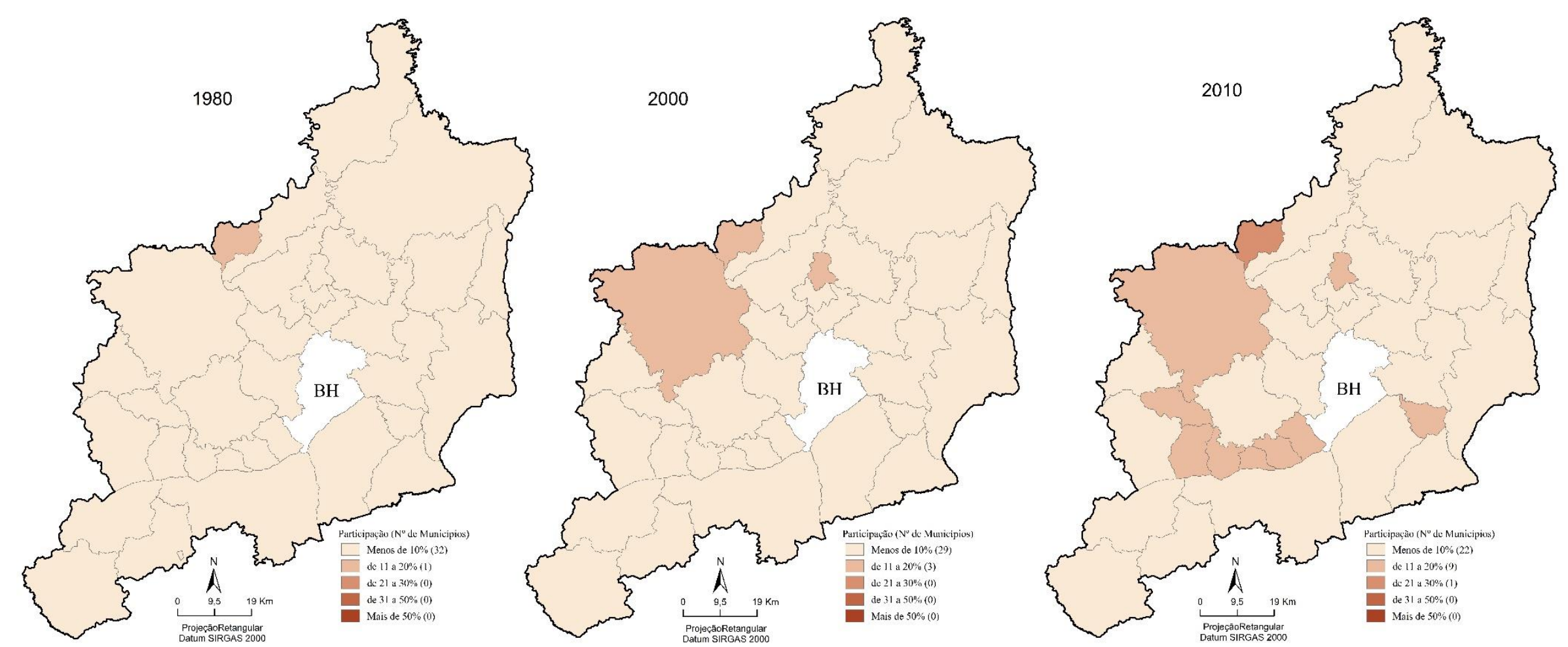

Figura 3: Participação relativa da população que trabalha e estuda no município de residência na PIA dos municípios da PMBH -

1980, 2000 e 2010

Fonte: Censos Demográficos de 1980, 2000 e 2010 (dados da amostra) 


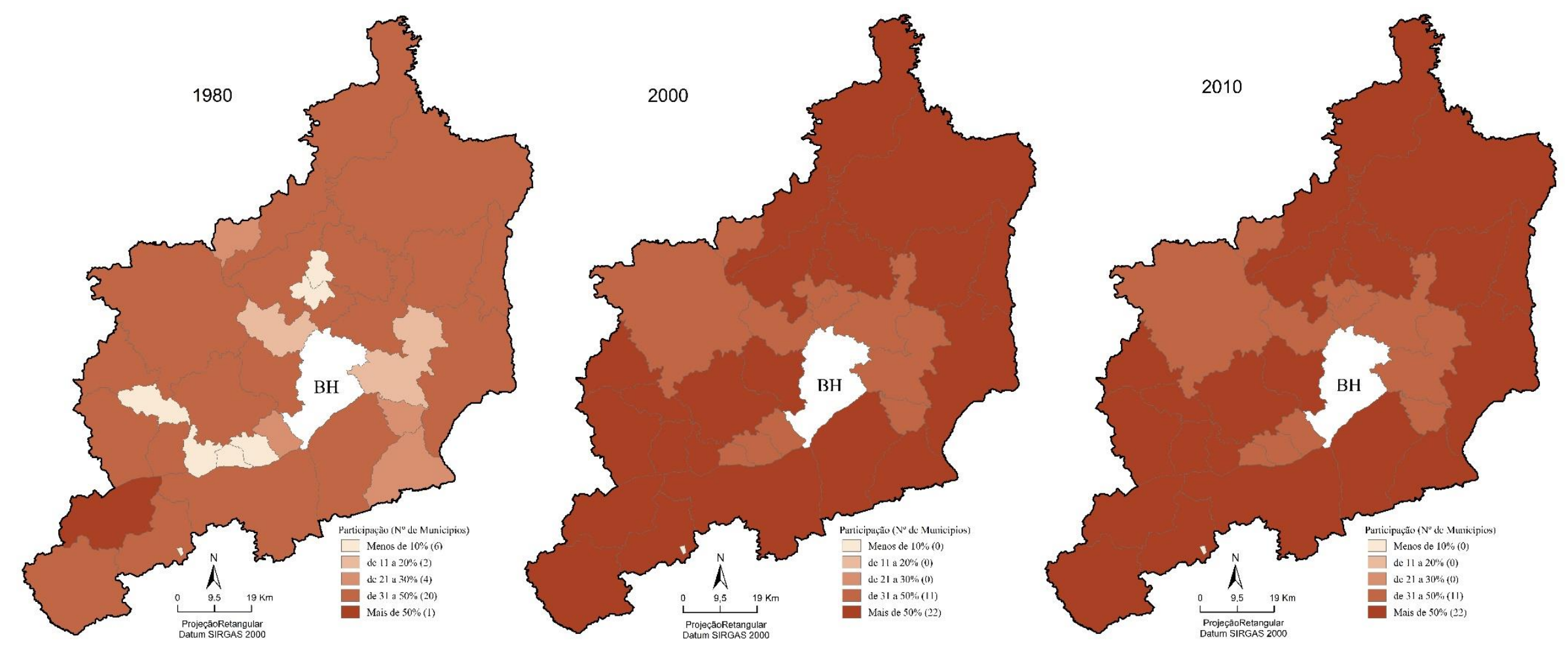

Figura 4: Participação relativa da população que trabalha e estuda no município de residência na PIA nos municípios da PMBH 1980, 2000 e 2010

Fonte: Censos Demográficos de 1980, 2000 e 2010 (dados da amostra) 
Tabela 2: Razão de Pendularidade (RP) nos municípios da PMBH em 1980, 2000 e 2010

\begin{tabular}{|c|c|c|c|c|c|}
\hline \multirow{2}{*}{ Município } & \multicolumn{5}{|c|}{ Razão de Pendularidade (RP) } \\
\hline & 1980 & 2000 & 2010 & $1980 / 2000$ & $2000 / 2010$ \\
\hline Raposos & 91,40 & 63,05 & 107,01 & $\downarrow$ & $\uparrow$ \\
\hline Ibirité & 114,65 & 88,70 & 104,38 & $\downarrow$ & $\mathbf{t}$ \\
\hline Sabará & 164,43 & 73,48 & 96,26 & $\downarrow$ & $\mathbf{t}$ \\
\hline Ribeirão das Neves & 230,60 & 82,54 & 94,23 & $\downarrow$ & $\boldsymbol{\mathbf { t }}$ \\
\hline Vespasiano & 17,47 & 59,23 & 74,06 & $\mathbf{1}$ & $\mathbf{1}$ \\
\hline Santa Luzia & 57,85 & 66,74 & 68,99 & $\boldsymbol{1}$ & $\boldsymbol{1}$ \\
\hline Sarzedo & $\mathrm{xxx}$ & 44,28 & 63,18 & & $\boldsymbol{1}$ \\
\hline Mário Campos & $\mathrm{xxx}$ & 40,68 & 59,38 & & $\boldsymbol{1}$ \\
\hline São José da Lapa & $\mathrm{xxx}$ & 45,37 & 56,08 & & $\boldsymbol{1}$ \\
\hline Esmeraldas & 6,29 & 38,65 & 54,77 & $\boldsymbol{1}$ & $\mathbf{1}$ \\
\hline Capim Branco & 55,19 & 44,20 & 51,21 & $\downarrow$ & $\boldsymbol{1}$ \\
\hline Nova Lima & 40,73 & 30,54 & 40,96 & $\downarrow$ & $\boldsymbol{1}$ \\
\hline Contagem & 64,95 & 38,27 & 40,90 & $\downarrow$ & $\boldsymbol{\uparrow}$ \\
\hline Rio Acima & 34,73 & 24,80 & 32,91 & $\downarrow$ & $\boldsymbol{1}$ \\
\hline Betim & 18,72 & 27,09 & 28,63 & $\boldsymbol{1}$ & $\boldsymbol{1}$ \\
\hline Confins & $\mathrm{Xxx}$ & 35,25 & 28,40 & & $\downarrow$ \\
\hline São Joaquim de Bicas & $\mathrm{xxx}$ & 20,51 & 28,38 & & $\boldsymbol{1}$ \\
\hline Caeté & 6,29 & 21,38 & 28,18 & $\mathbf{1}$ & $\boldsymbol{1}$ \\
\hline Lagoa Santa & 15,74 & 18,36 & 25,42 & $\boldsymbol{1}$ & $\boldsymbol{\uparrow}$ \\
\hline Juatuba & $\mathrm{xxx}$ & 20,28 & 24,53 & & $\boldsymbol{1}$ \\
\hline Pedro Leopoldo & 11,95 & 14,38 & 24,40 & $\boldsymbol{1}$ & $\boldsymbol{1}$ \\
\hline Igarapé & 12,65 & 17,29 & 22,31 & $\boldsymbol{1}$ & $\boldsymbol{1}$ \\
\hline Matozinhos & 24,79 & 16,34 & 19,98 & $\downarrow$ & $\boldsymbol{\top}$ \\
\hline Florestal & 16,87 & 7,06 & 18,30 & $\downarrow$ & $\boldsymbol{1}$ \\
\hline Mateus Leme & 10,49 & 14,05 & 17,40 & $\downarrow$ & $\boldsymbol{1}$ \\
\hline Brumadinho & 14,80 & 15,46 & 16,56 & $\boldsymbol{1}$ & $\boldsymbol{1}$ \\
\hline Nova União & 13,15 & 13,52 & 15,13 & $\boldsymbol{1}$ & $\boldsymbol{1}$ \\
\hline Jaboticatubas & 0,49 & 6,67 & 11,43 & $\boldsymbol{1}$ & $\boldsymbol{1}$ \\
\hline Rio Manso & 0,41 & 5,87 & 11,39 & $\boldsymbol{1}$ & $\boldsymbol{1}$ \\
\hline Taquaraçu de Minas & 6,88 & 4,58 & 10,87 & $\downarrow$ & $\boldsymbol{1}$ \\
\hline Baldim & 2,82 & 7,81 & 8,87 & $\boldsymbol{1}$ & $\boldsymbol{1}$ \\
\hline Itatiaiuçu & 3,35 & 7,02 & 7,58 & $\boldsymbol{1}$ & $\boldsymbol{1}$ \\
\hline Itaguara & 1,16 & 6,21 & 6,51 & 1 & $\uparrow$ \\
\hline
\end{tabular}

Fonte: Censos Demográficos de 1980, 2000 e 2010 (dados da amostra) 


\section{CONCLUSÕES E CONSIDERAÇÕES FINAIS}

Desde a década de 1980, os possíveis efeitos do processo de desconcentração espacial e dispersão da população têm atraído atenção especial de vários pesquisadores brasileiros. Depois de décadas em que o país enfrentou uma forte concentração da população e das atividades econômicas nas principais metrópoles do Sudeste, surgiram evidências acerca da possível mudança de padrão. Mesmo que nossa realidade social e econômica seja eminentemente distinta, várias tentativas buscaram avaliar essa hipótese para o caso brasileiro. Ainda que esse debate não tenha se traduzido em consenso, algumas evidências parecem sugerir, se não uma desconcentração nos moldes clássicos, pelo menos o fortalecimento de determinadas espacialidades além do core metropolitano. A despeito das incertezas, são pouco numerosas as pesquisas que enfatizam os movimentos espaciais da população, seja pela definição clássica da migração, seja pela dita mobilidade pendular.

Nesse contexto, a Região Metropolitana de Belo Horizonte compreende um espaço especialmente peculiar. Na metade do século passado a capital do estado tinha pouco mais de 350 mil habitantes. Em menos de cinquenta anos Belo Horizonte teve um forte surto de crescimento demográfico e um posterior arrefecimento, resultado, em boa medida, da inversão no saldo migratório intrametropolitano. A partir desse momento, vários centros urbanos se fortaleceram na periferia metropolitana, apresentando níveis de crescimento populacional significativamente superior ao do núcleo e um grande fluxo de imigrantes. Se a dispersão espacial da população residente é insuficiente para caracterizar um quadro de desconcentração espacial, como proposto na economia regional, parece haver outros sinais de ganho de autonomia econômica em diversos espaços além do core. Essas evidências vão além de realidade encontrada em Contagem e Betim (vetor Oeste), importantes centros de expansão do parque industrial, mas também podem ser identificadas em municípios do eixo norte da RM, como em Ribeirão das Neves, Santa Luzia e Vespasiano.

Uma forma de avaliar as alterações na centralidade do espaço metropolitana é feita pela análise dos movimentos pendulares. Com base nos dados dos três últimos censos foi possível assinalar um sensível crescimento dos fluxos do tipo residência/trabalho nos municípios da região com destino a Belo Horizonte e periferia metropolitana. Paralelamente, e associado a essa mudança, em grande parte dos municípios da periferia houve um expressivo crescimento no volume daqueles que trabalhavam ou estudavam no próprio município de residência. Ainda que pareça contraditório, uma análise acerca dos fluxos pendulares de população entre os municípios da periferia metropolitana parece indicar que, embora Belo Horizonte tenha mantido sua centralidade, tem havido um ganho de autonomia 
em um número razoável de municípios na região. Vários municípios antes descritos como típicas "cidades dormitórios" nas décadas de 1960 e 1970, além de ampliar suas inter-relações com o core, apresentam forte desenvolvimento de determinadas funcionalidades eminentemente urbanas, o que tem permitido que uma crescente parcela da população local tivesse suas atividades econômicas/profissionais desenvolvidas no próprio município de residência, o que tem diminuído a necessidade de deslocamento para o núcleo metropolitano.

\section{REFERÊNCIAS BIBLIOGRÁFICAS}

AGUILERA, A. Growth in commuting distances in French Polycentric Metropolitan Areas: Paris, Lyon and Marseille. Urban Studies, v. 42, n. 9, 2005, p.1537-1547.

AZZONI, C. Indústria e Reversão da Polarização no Brasil. Ensaios Econômicos, IPE/USP, São Paulo, n.58, 1986.

BAENINGER, R. O processo de urbanização no Brasil: características e tendências. In: BÓGUS, L.M.M.; WANDERLEY, L.E.W.(orgs.). A luta pela cidade em São Paulo. Cortez Editora. São Paulo, 1992, p. 11-28.

BRITO, F. Mobilidade espacial e expansão urbana: o caso da Região Metropolitana de Belo Horizonte. Anais do X Encontro de Estudos Populacionais. Brasília, 1992, v.2, p.771-788.

CARVAlHO, J. A. M., RIGOTTI, J. I. Análise das metodologias de mensuração das migrações. In: ENCONTRO NACIONAL SOBRE MIGRAÇÃO, 1998, Curitiba. Anais... Curitiba: IPARDES/ABEP, 1998.

CASTEllo BRANCO, M. L. G.; FIRKOWSKI, O. L. F. C.; MOURA, R. Movimento pendular: abordagem teórica e reflexões sobre o uso do indicador. In: XI ENCONTRO NACIONAL DA ANPUR, 2005, Salvador. Anais... Salvador, 2005.

CUNHA, J. M. P. Redistribuição espacial da população: tendências e trajetória. São Paulo em Perspectiva, 17(3-4), 2003, p. 218-233.

CRUZ, M. F. Condicionantes Metropolitanos para Políticas Públicas: Análise dos Transportes Coletivos na Região Metropolitana de São Paulo (1999-2009). Dissertação (Mestrado em Administração Pública e Governo), Fundação Getúlio Vargas, São Paulo, 2010. DINIZ, C.C. "Desenvolvimento poligonal no Brasil; nem desconcentração, nem contínua polarização". Nova Economia - Revista de Ciências Econômicas da UFMG, Belo Horizonte, vol. 31, n. 11, 1993, p. 35-64.

DURANTON, G. Delineating metropolitan areas: Measuring spatial labour market networks through commuting patterns. Processed, Pennsylvania, 2013. 
FREY, W. H.; SPEARE, Jr, A. Metropolitan Areas as Functional Communities: A Proposal for a New Definition. Research Report, Population Studies Center, University of Michigan USA, 1992.

GREENWOOD, M. Migrações internas nos Estados Unidos; uma revisão da literatura. In: MOURA, A. M. (Coord). Migração interna; textos selecionados. Fortaleza: Banco do Nordeste do Brasil, 1980, p. 733-77. 1980.

JARDIM, A de P. Reflexões sobre a mobilidade pendular. In: OLIVEIRA, L. A. P. de; OLIVEIRA, A. T. R. de. Reflexões sobre os deslocamentos populacionais no Brasil. Rio de Janeiro: IBGE, 2011.

LOBO, C. Dispersão espacial da população no Brasil. Mercator, v. 15, n. 3, 2016 a.

LOBO, C. Mobilidade pendular e a dispersão espacial da população: evidências com base nos fluxos com destino às principais metrópoles brasileiras. Caderno de Geografia, v.26, n.45, 20. LOBO, C.; MATOS, R., CARDOSO, L., COMINI, L.; PINTO, G. Expanded commuting in the metropolitan region of Belo Horizonte: evidence for reverse commuting. Revista Brasileira de Estudos de População, v. 32, n. 2, p. 219-233, 2015.

LOBO, C.; CARDOSO, L.; MATOS, R. Mobilidade pendular e centralidade espacial: considerações sobre o caso da Região Metropolitana de Belo Horizonte. In: XXIII ANPET Congresso de Pesquisa e Ensino em Transportes. Vitória/ES, 2009.

MARES GUIA, V. R. A gestão na Região Metropolitana de Belo Horizonte: avanços e limites. In: FERNANDES, E. (org.). Direito urbanístico e política urbana no Brasil. Belo Horizonte: Del Rey, 2001.

MARTINE, G.. A redistribuição espacial da população brasileira durante a década de 80. Textos para Discussão 329, Brasília, IPEA, 1994. 43p.

MARTINE, G. Migração e metropolização. São Paulo em Perspectiva. São Paulo, Fundação SEADE 1(2)7, 1987.

MATOS, R. "Questões teóricas acerca dos processos de concentração e desconcentração da população no espaço”. In: Revista Brasileira de Estudos Populacionais. São Paulo, 1995, p. $35-58$.

MATOS, R. e BENINGER, R. Migração e urbanização no Brasil: processos de concentração e desconcentração espacial e o debate recente. Cadernos do Leste. IGC/UFGM, v.1, n.1, Belo Horizonte, 2004, p.7-44.

MORRILL, R.; CROMARTIE, J. e HART, G. Metropolitan, urban, and rural commuting areas: toward a better depiction of the United States settlement system. Urban Geography, 1999, 20, 8, p. 727-748. 
MOURA, R.; BRANCO, M. L. G. C. e IRKOWSKI, O. L. C. de F.. Movimento pendular e perspectivas de pesquisas em aglomerados urbanos. São Paulo em Perspectiva, v. 19, n. 4, 2005, p. 121-133.

NEGRI, B. Concentração e desconcentração industrial em São Paulo (1880-1990). Campinas: Ed. UNICAMP, 1996.

OJIMA, R. Fronteiras metropolitanas: um olhar a partir dos movimentos pendulares. Revista Paranaense de Desenvolvimento, Curitiba, n.121, 2011, p.115-132.

OJIMA, R.; MARANDOLA JR, E.; PEREIRA, R. H. M.; DA SILVA, R. B. O estigma de morar longe da cidade: repensando o consenso sobre as "cidades-dormitório" no Brasil. Cadernos metrópole, v. 12, n. 24, 2010, p. 395-415.

PATARRA, N. Dinâmica populacional e urbanização no Brasil: período pós-30. In: PEREIRA, R. H. M.; HERRERO, V. Mobilidade pendular: uma proposta teóricometodológica. Rio de Janeiro: Ipea (Texto para Discussão, n. 1.395), 2009. Disponível em:〈http://goo.gl/Kz6f2Z〉. Acesso em: 20 abr. 2014.

REDWOOD III, J. Reversion de polarizacion, ciudades secundarias y eficiencia en el desarrollo nacional: una vison teorica aplicada al Brsil contemoraneo. Revista Latinoamericana de Estudios Urbanos Regionales, Santiago, vol 11, n.32, dez. 1984.

RICHARDSON, H. "Polarization reversal in developing countries". The Regional Science Association Papers, Los Angeles, vol. 45, nov. 1980.

RIGOTTI, J. I. R. Técnicas de mensuração das migrações a partir de dados censitários: aplicação aos casos de Minas Gerais e São Paulo. Belo Horizonte: UFMG/CEDEPLAR (tese de doutorado em demografia), 1999.

RIGOTTI, J. I. R. e RODRIGUES, J. N. Distribuição espacial da população na região Metropolitana de Belo Horizonte. Anais do IX Encontro de Estudos Populacionais. Caxambú,1994, v.1, p.435-456

TASCHNER, S. P. e BÓGUS, L.M.M. Mobilidade Espacial da População Brasileira: Aspectos e Tendências. Revista Brasileira de Estudos de População, jul-dez, 1986.

TOWNROE, P. e KEEN, D. M. "Polarization reversal in the state of São Paulo, Brazil". Journal of the Regional Studies Association, Cambridge, vol. 18, n. 1, fev. 1984. 